\title{
AC Hopping Conductance in Nanocomposite Films with Ferromagnetic Alloy Nanoparticles in a $\mathrm{PbZrTiO}_{3}$ Matrix
}

\author{
T.N. KOLTUNOWICZ, ${ }^{1,5}$ P. ZUKOWSKI, ${ }^{1}$ O. BOIKO,${ }^{1}$ A. SAAD, ${ }^{2}$ \\ J.A. FEDOTOVA ${ }^{3}$ A.K. FEDOTOV,${ }^{4}$ A.V. LARKIN, ${ }^{4}$ and J. KASIUK ${ }^{3}$
}

1.-Lublin University of Technology, 20-618 Lublin, Poland. 2.-Physics Department, Al Balqa Applied University, P.O. Box 4545, Amman 11953, Jordan. 3.-National Center for Particles and High Energy Physics of Belarusian State University, 220088 Minsk, Belarus. 4.-Belarusian State University, 220030 Minsk, Belarus. 5.—e-mail: t.koltunowicz@pollub.pl

In this work, the temperature and frequency dependences of the real part of the admittance $[\sigma(f, T)]$ of annealed nanocomposite films containing $\mathrm{Co}_{45}$ $\mathrm{Fe}_{45} \mathrm{Zr}_{10}$-based nanoparticles covered with native oxides and embedded in a doped $\mathrm{PbZrTiO}_{3}$ ferroelectric matrix were studied. The nanocomposites studied were deposited by ion sputtering a complex target in a mixed $\mathrm{Ar} / \mathrm{O}_{2}$ atmosphere followed by a 15-min annealing process (with steps of $25 \mathrm{~K}$ ) in air in the temperature range of $398 \mathrm{~K} \leq T_{\mathrm{a}} \leq 573 \mathrm{~K}$. The $\sigma(f, T)$ of the annealed samples was measured in the temperature range of $77 \mathrm{~K}<T_{\mathrm{p}}<373 \mathrm{~K}$ at frequencies of $50 \mathrm{~Hz}<f<1 \mathrm{MHz}$. The observed $\sigma(f, T)$ dependences confirmed that the annealed samples displayed the effects of negative capacitance over the whole frequency and temperature ranges studied because of the pronounced oxidation of the nanoparticles. The $\sigma(f, T)$ dependences obtained are described using an earlier-developed AC hopping conductance model. Comparisons between experimental and simulation results allow the model parameters to be estimated, such as the activation energies of the hopping conductance and the lifetimes of the electrons in the nanoparticles.

Key words: Admittance, electronic transport, hopping conductance, nanocomposite

\section{INTRODUCTION}

Nanocomposites that include nanoparticles made of ferromagnetic metals or alloys embedded in different matrices have great potential for some industrial applications. Ceramics ${ }^{1}$ low-conductive metallic materials, ${ }^{2}$ and even insulating liquids ${ }^{3,4}$ can be used as matrices to impart composites with improved mechanical, ${ }^{1,2}$ magnetic,${ }^{5-7}$ and electrical properties. $^{8,9}$ Particular attention has been paid to composites containing granules of soft ferromagnetic highly conductive metallic alloys about a few nanometers in size, randomly distributed in low-conductive matrices including dielectric, ferroelectric, or piezoelectric substances. It is of great interest to apply such materials particularly in

(Received November 19, 2014; accepted February 5, 2015; published online March 13, 2015) electrical engineering, e.g., in capacitors and highohmic resistors to protect systems from problems including high-frequency electromagnetic radiation, and in transducers of temperature and magnetic and electric fields. ${ }^{10}$

Besides, metal-dielectric nanocomposites are excellent model systems to study fundamental effects in heterogeneous media including percolation, hopping conductance, and weak localization. ${ }^{11}$ In accordance with percolation theory, ${ }^{12}$ the extreme values of some physical parameters (including the electrical and magnetic properties) in nanocomposites have been observed around the threshold concentration $\left(x_{\mathrm{c}}\right)$ of the high-conductive phase, corresponding to the onset of a current-conducting net of nanoparticles. In binary metaldielectric composites, the $x_{\mathrm{c}}$ value is defined as the percolation threshold. When the volume ratio $(x)$ increases and approaches $x_{\mathrm{c}}$, the composite 
undergoes an insulator-metal transition. Below $x_{\mathrm{c}}$ the composite behaves as a dielectric (highly resistive material), whereas beyond $x_{\mathrm{c}}$ its behavior becomes metallic like, owing to the formation of a whole net of low-resistive current-conducting routes in the dielectric matrix. The $x_{c}$ value is strongly dependent on the relative conductivities of the highand low-conductive phases, $x$, and the concentration of chemically active impurities incorporated into the matrix and/or metallic filler during synthesis and further heat treatments. In this context, clarification of the correlation between deposition conditions, $x$ values, the phase composition of the nanoparticles, matrices, and the integrated electric properties of the nanocomposites becomes important.

In our earlier studies on $\left(\mathrm{Fe}_{45} \mathrm{Co}_{45} \mathrm{Zr}_{10}\right)_{x}$ $\left(\mathrm{Al}_{2} \mathrm{O}_{3}\right)_{(100-x)}$ nanocomposite granular films, ${ }^{8,13-16}$ it was shown that deposition conditions play the key role in the phase composition of the films. In particular, transmission electron microscopy, x-ray diffraction (XRD) analysis, and Mössbauer spectroscopy (MS) measurements revealed that adding oxygen to the sputtering atmosphere results in formation of CoFe-based oxide shells around the FeCoZr nanoparticles. ${ }^{17}$ Formation of such a metallic core/oxide shell structure of the nanoparticles inside the matrix induces radical modification of the electric and magnetic properties of the nanocomposite films as a whole. Also, the formation of a core/shell structure shifts $x_{\mathrm{c}}$ up to 55 at.\%, compared with 44 at.\% to 47 at.\% for films deposited in a pure $\mathrm{Ar}$ gas atmosphere.

It has also been established that some granular nanocomposites exhibit the effect of negative capacitance (NC) with positively phase-shifted angles between the current and voltage applied when measuring the reactive part of the admittance. ${ }^{18-20}$ The observation of $\mathrm{NC}$ is associated with a dominant inductive-like $(L)$ contribution in the imaginary part of the admittance, which could be utilized to produce microscale planar inductive elements in electrical engineering of integrated circuits. It has been proved that the dominant $L$-contribution is related to the formation of the core/shell structure of the nanoparticles; $;, 13-16,19,20$ namely, it strongly increased with growth of the semiconducting $\mathrm{CoFe}$-based oxide shell thickness. Technologically, the formation of the core/ shell nanoparticle structure can be obtained by either annealing in air (for $\mathrm{FeCoZr}$-alumina and $\mathrm{FeCoZr}$ $\mathrm{CaF}_{2}$ nanocomposites ${ }^{15,21}$ ) or adding oxygen to the atmosphere during synthesis (for $\mathrm{FeCoZr}-\mathrm{PbZrTiO}{ }_{3}$ nanocomposites ${ }^{17,19,22}$ ).

The experimentally observed frequency dependences of admittance with $\mathrm{NC}$ in as-deposited and annealed $\mathrm{FeCoZr}$-alumina and as-deposited FeCoZr-PbZrTiO ${ }_{3}$ nanocomposite films can be explained by the hopping AC conductance model developed in Refs. 9, 19, and 22. This model takes into account that, before an electric field is applied, the electrons are localized in potential wells (namely, nanoparticles with a core/shell structure embedded in a dielectric matrix). The application of a weak $\mathrm{AC}$ electric field causes the electrons to jump from one neutral well to another (on the order of $10^{-13} \mathrm{~s}$ ) following the phase of the applied electric field. At first, electrons jump between two neutral potential wells (nanoparticles), forming a dipole containing two charged particles, which enhances the dielectric permeability of the material. ${ }^{19}$ Interactions between electrons trapped by neighboring metallic nanoparticles (potential wells), and the polarized dielectric matrix, lead to the breakdown of the equal probability $(p)$ of electrons jumping forward and backward following the direction of the applied AC electric field. Consequently, the electrons jump back into the charged wells and their forward jumps to the next wells are delayed by a time $\tau_{\mathrm{m}}$. In accordance with the developed model, the frequency region in which the delay is substantial can be determined by

$$
f \leq \frac{1}{2 \tau_{\mathrm{m}}} \approx f_{\min }
$$

In this case, the frequency dependence of the real part of the impedance can be written as the known Mott relation ${ }^{23}$

$$
\sigma(f) \approx \sigma_{0} f^{\alpha(p)},
$$

where $\sigma_{0}$ is a coefficient and the exponent $\alpha$ is the frequency factor. Compared with the Mott model where $\alpha \approx 0.8$, in our model this factor determines the jump probability $p$ and therefore depends on the change in the frequency in the range $0<\alpha<2$. In this case, the $\sigma(f, T)$ dependences for the composites studied in the dielectric regime should be characterized by a sigmoid-like shape ${ }^{21,24,25}$ displaying three characteristic frequency regions: $\sigma_{\mathrm{L}} \approx$ const. for low frequencies, $\sigma_{\mathrm{H}} \approx$ const. for high frequencies, where $\sigma_{\mathrm{H}}>\sigma_{\mathrm{L}}$, and an intermediate frequency region described by Eq. 2. This nearly sigmoid-like behavior of $\sigma(f, T)$ allows the factor $\alpha$ and the probability density $p$ to be extracted using the developed model and the characteristic parameters of the model to be estimated, namely the energies of activation for dipole formation and mean lifetime $\tau_{\mathrm{m}}(1)$ of an electron in a nanoparticle.

The presence of the NC effect in as-deposited and annealed $\left(\mathrm{Fe}_{45} \mathrm{Co}_{45} \mathrm{Zr}_{10}\right)_{x}\left(\mathrm{Al}_{2} \mathrm{O}_{3}\right)_{(100-x)}$ films can be primarily controlled by the volume ratio and the phase composition of the oxide shells around the metallic nanoparticles; ${ }^{7-9,13-17,22}$ namely, the shells should have semiconducting properties and be as thick as possible. In addition, the phase composition and volume contribution of the shells depend on several factors: (1) the composition of the films with respect to the percolation threshold (progressive oxidation of metallic nanoparticles with $x$ growth is shown in Ref. 26), (2) partial oxygen pressure in the sputtering atmosphere, and (3) annealing in air. 
Detailed investigation of the structure and phase composition of $\mathrm{FeCoZr}-\mathrm{PbZrTiO}_{3}$ films sputtered in an oxygen-containing atmosphere ${ }^{19,22}$ showed more advanced oxidation, thus leading to the higher contribution from the oxide shells. Based on the earlier experimental results and modeling, such phase composition should favor a high NC effect, which could be further enhanced by annealing of the films. Therefore, the present paper is focused on the influence of annealing $\mathrm{FeCoZr}-\mathrm{PbZrTiO}_{3}$ films in air on the NC effect. Also the applicability of the hopping conductivity model to the description of this effect in the films is studied.

\section{EXPERIMENTAL PROCEDURES}

Nanocomposite $\left(\mathrm{Fe}_{45} \mathrm{Co}_{45} \mathrm{Zr}_{10}\right)_{x}\left(\mathrm{PbZrTiO}_{3}\right)_{(100-x)}$ films were deposited by ion-beam sputtering of a complex target in a vacuum chamber. Sputtering was performed in a mixed argon-oxygen atmosphere in a chamber evacuated with a mixture of $\mathrm{Ar} /$ $\mathrm{O}_{2}$ under partial pressures of $P_{\mathrm{Ar}}=6.7 \mathrm{mPa}$ and $P_{\mathrm{O} 2}=3.2 \mathrm{mPa}$, respectively. The method to manufacture the films and the characterization of their structures are described in detail elsewhere. ${ }^{15,26-28}$ The compound target contained $\mathrm{Fe}_{45}$ $\mathrm{Co}_{45} \mathrm{Zr}_{10}$ alloy plates with $\mathrm{PbZrTiO}_{3}$ stripes arranged on their surfaces. The irregular distribution of the $\mathrm{PbZrTiO}_{3}$ stripes (with continuously increasing spaces between them) on the target surfaces allows synthesis of films with variable metalto-dielectric ratios, $x$ (depending on the mutual arrangement of the targets and substrates) in one technological cycle.

The films were sputtered at $373 \mathrm{~K}$ onto glass ceramic substrates $250 \mathrm{~mm}$ in length, $50 \mathrm{~mm}$ in width, and $0.6 \mathrm{~mm}$ in thickness for the electric measurements. The chemical compositions of the films were verified by microprobe x-ray analysis (EDX) with a scanning electron microscope (SEM, LEO1455VP) and a Rutherford backscattering (RBS) method with accuracy of $\sim 1$ at. $\%{ }^{26,29,30}$ The thicknesses of the films ranged from $1 \mu \mathrm{m}$ to $2 \mu \mathrm{m}$ as estimated by SEM on cleaved regions of the samples with accuracy of approximately $3 \%$ to $4 \%$.

Ten nanocomposite $\left(\mathrm{Fe}_{45} \mathrm{Co}_{45} \mathrm{Zr}_{10}\right)_{x}\left(\mathrm{PbZrTiO}_{3}\right)_{(100-x)}$ samples with $x$ ranging from 39.9 at. $\%$ to 88.4 at.\% were studied, as well as a sample of metallic $\left(\mathrm{Fe}_{45}\right.$ $\mathrm{Co}_{45} \mathrm{Zr}_{10}$ ) film (with $x=100$ at.\%), which was produced under identical conditions to the nanocomposite films. The electrically tested samples were covered with four silver stripes, which act as electric probes (two current and two potential probes). Four-probe admittance measurements were performed using a digital LCR meter (HIOKI 3532 HiTester, Japan) in the frequency range from $50 \mathrm{~Hz}$ to $1 \mathrm{MHz}$. All measurements were carried out within the temperature range of $77 \mathrm{~K}<T_{\mathrm{p}}<373 \mathrm{~K}$, where the temperature was recorded by a thermocouple using an Agilent 34970A multimeter. During the experiments, the changes in the phase shift and the full resistance of the studied samples were fixed to calculate the real and imaginary parts of the admittance. This procedure is described in detail elsewhere. ${ }^{31,32}$ The absolute values of the admittance were measured with accuracy of $\sim 5 \%$, whereas the specific admittance was measured with accuracy of less than $10 \%$ because of the errors in the measured thicknesses and the distances between the potential probes in the samples. The as-deposited samples were subjected to a set of 15-min isochronous annealing within the temperature range of $373 \mathrm{~K}<T_{\mathrm{a}}<673 \mathrm{~K}$ with steps of $25 \mathrm{~K}$.

\section{RESULTS AND DISCUSSION}

The $\mathrm{PbZrTiO}_{3}$ matrix in the studied nanocomposite films was selected because of two specific features. First, $\mathrm{PbZrTiO}_{3}$ is a less corrosion-resistant material than alumina, allowing it to make a much higher contribution to the oxidized metallic fraction in $\left(\mathrm{Fe}_{45} \mathrm{Co}_{45} \mathrm{Zr}_{10}\right)_{x}\left(\mathrm{PbZrTiO}_{3}\right)_{(100-x)}$ films. This is favorable for enhancing the NC effect as well as to shift it to the room-temperature region (which is preferable for potential applications). Second, $\mathrm{PbZrTiO}_{3}$ possesses ferroelectric and piezoelectric properties in the crystalline state, expanding the possibilities for tuning the magnetic and electric properties of nanocomposites if required for a particular application.

Before the admittance is characterized, a brief review of the phase structure of $(\mathrm{FeCoZr})_{x}$ $\left(\mathrm{PbZrTiO}_{3}\right)_{(100-x)}$ films is presented based on results from XRD analysis, x-ray absorption spectroscopy (XAS), MS, Raman spectroscopy, magnetometry, and electric conductivity measurements. ${ }^{22,26,29,33}$ Mössbauer and Raman spectra collected at room temperature from selected $(\mathrm{FeCoZr})_{x}\left(\mathrm{PbZrTiO}_{3}\right)_{(100-x)}$ films fabricated at $P_{\mathrm{O}} \leq 3.2 \mathrm{mPa}$ are shown in Fig. 1 . Fitting of Mössbauer spectra in Fig. 1a shows that, in films with $x<67$ at.\%, synthesized at low oxygen partial pressures, the nanoparticles were fully oxidized and contained various types of oxide, namely $\mathrm{Fe}(\mathrm{Co})_{3} \mathrm{O}_{4}$ or $\mathrm{Fe}(\mathrm{Co})_{2} \mathrm{O}_{3}$ (characterized with the superparamagnetic doublet, $\delta=0.3 \mathrm{~mm} / \mathrm{s}$ to $0.45 \mathrm{~mm} /$ $\mathrm{s}, \Delta E=0.9 \mathrm{~mm} / \mathrm{s}$ to $1.2 \mathrm{~mm} / \mathrm{s})$, and $\left(\mathrm{Fe}_{x} \mathrm{Co}_{1-x}\right)_{1-\delta} \mathrm{O}$ (characterized with the doublet, $\delta=0.9 \mathrm{~mm} / \mathrm{s}$ to $1.1 \mathrm{~mm} / \mathrm{s}, \Delta E=1.7 \mathrm{~mm} / \mathrm{s}$ to $1.8 \mathrm{~mm} / \mathrm{s}$ ). This means that the (FeCoZr)-based nanoparticles in a $\mathrm{PbZrTiO}_{3}$ matrix cannot be characterized by the metal core/ oxide shell structure typically observed for the FeCoZr-alumina nanocomposites that we studied previously. ${ }^{22,26,29}$ Taking into account the similarities of the oxide phase compositions in the nanoparticles in $\mathrm{FeCoZr}-\mathrm{PbZrTiO}_{3}$ and $\mathrm{FeCoZr}-\mathrm{Al}_{2} \mathrm{O}_{3}$ films, identified by comprehensive analysis of the MS, XAS, and XRD data, it is believed that the nanoparticles in FeCoZr-PbZrTiO ${ }_{3}$ films have an oxide core/oxide shell structure. In this case, the core may comprise the oxides $\mathrm{Fe}(\mathrm{Co})_{3} \mathrm{O}_{4}$ and $\mathrm{Fe}(\mathrm{Co})_{2} \mathrm{O}_{3}$, while the shell may consist of $\left(\mathrm{Fe}_{x} \mathrm{Co}_{1-x}\right)_{1-\delta} \mathrm{O}$. Possible contributions from a small quantity of zirconium oxide to addi- 
(a)
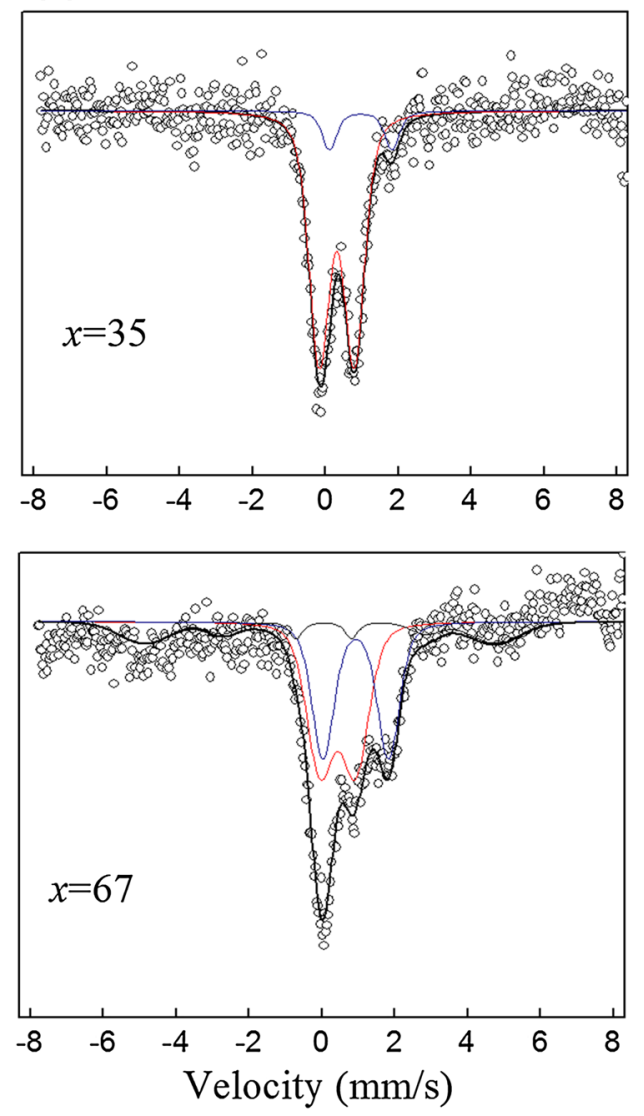
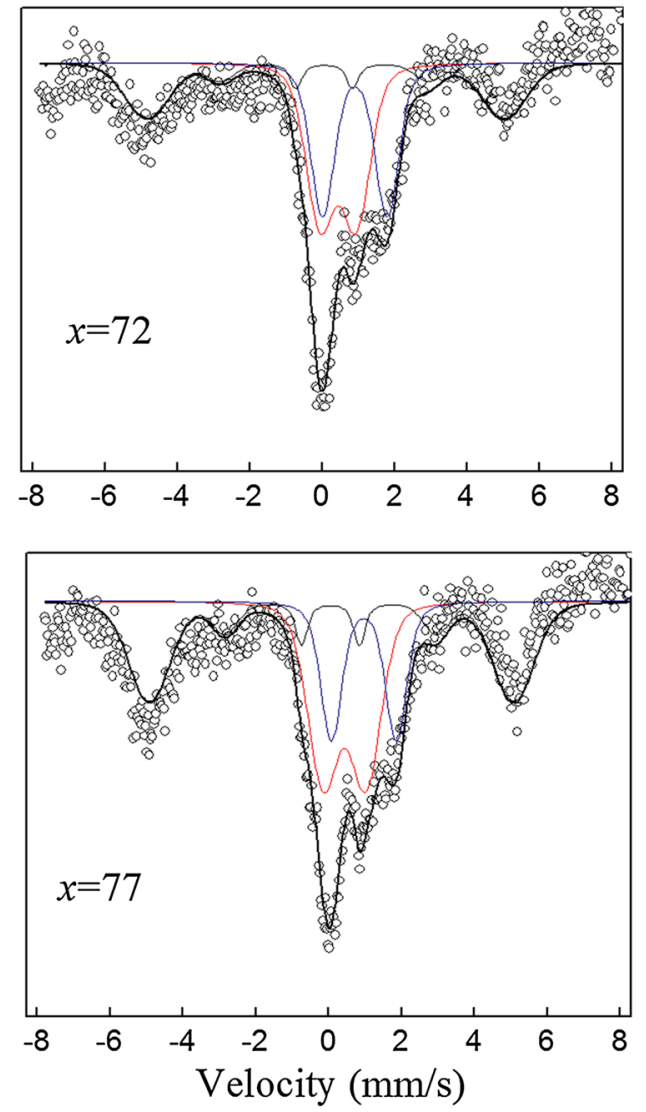

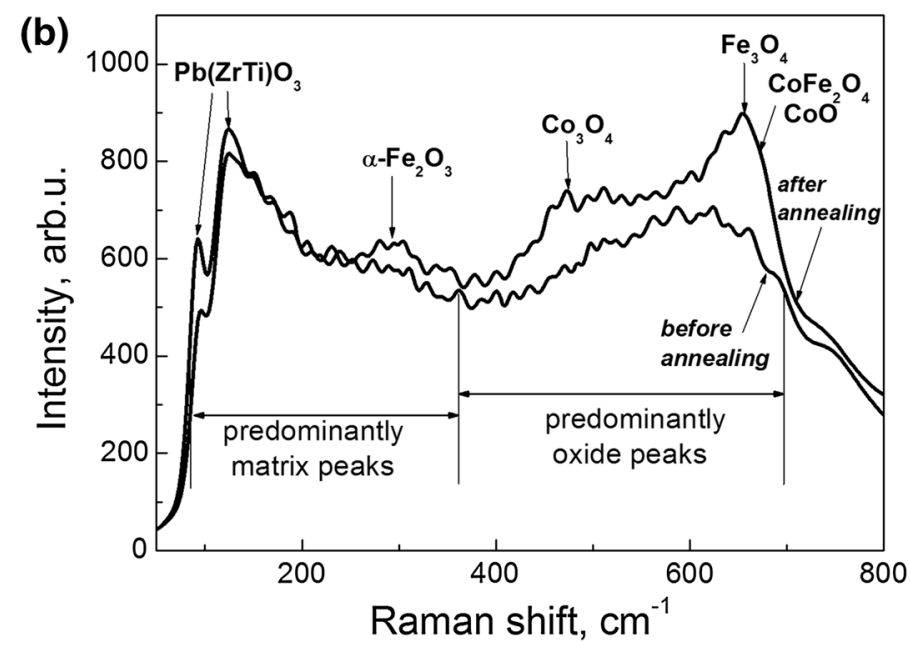

Fig. 1. Mössbauer spectra of $(\mathrm{FeCoZr})_{x}(\mathrm{PZT})_{(100-x)}\left(35\right.$ at.\% $\leq x \leq 77$ at.\%) fabricated at $P_{\mathrm{O}}=2.4 \times 10^{-3} \mathrm{~Pa}(\mathrm{a})$ and Raman spectra of assintered and annealed (FeCoZr $)_{63}(\mathrm{PZT})_{37}$ fabricated at $P_{\mathrm{O}}=3.2 \times 10^{-3} \mathrm{~Pa}(\mathrm{~b})$.

tionally stabilize the oxide shells cannot be excluded, as it is proved by EXAFS and reported in Ref. 34 .

Mössbauer spectra of films with $x>67$ at. $\%$ (Fig. 1a) show that films contain superparamagnetic $\mathrm{Fe}(\mathrm{Co})_{3} \mathrm{O}_{4}$ or $\mathrm{Fe}(\mathrm{Co})_{2} \mathrm{O}_{3}$ and $\left(\mathrm{Fe}_{x} \mathrm{Co}_{1-x}\right)_{1-\delta} \mathrm{O}$ oxides (characterized with two doublets) and ferromagnetic metallic $\alpha-\mathrm{FeCoZr}$ nanoparticles (or their agglomerations). The latter phase is associated with the sextet which appears in the spectra for $x \geq 67$ at.\%.

Raman spectroscopy performed on as-prepared $(\mathrm{FeCoZr})_{63}(\mathrm{PZT})_{37}$ film sputtered at $P_{\mathrm{O}}=3.2 \times$ $10^{-3} \mathrm{~Pa}$ (Fig. 1b) reveals several peaks in the range 
(a)
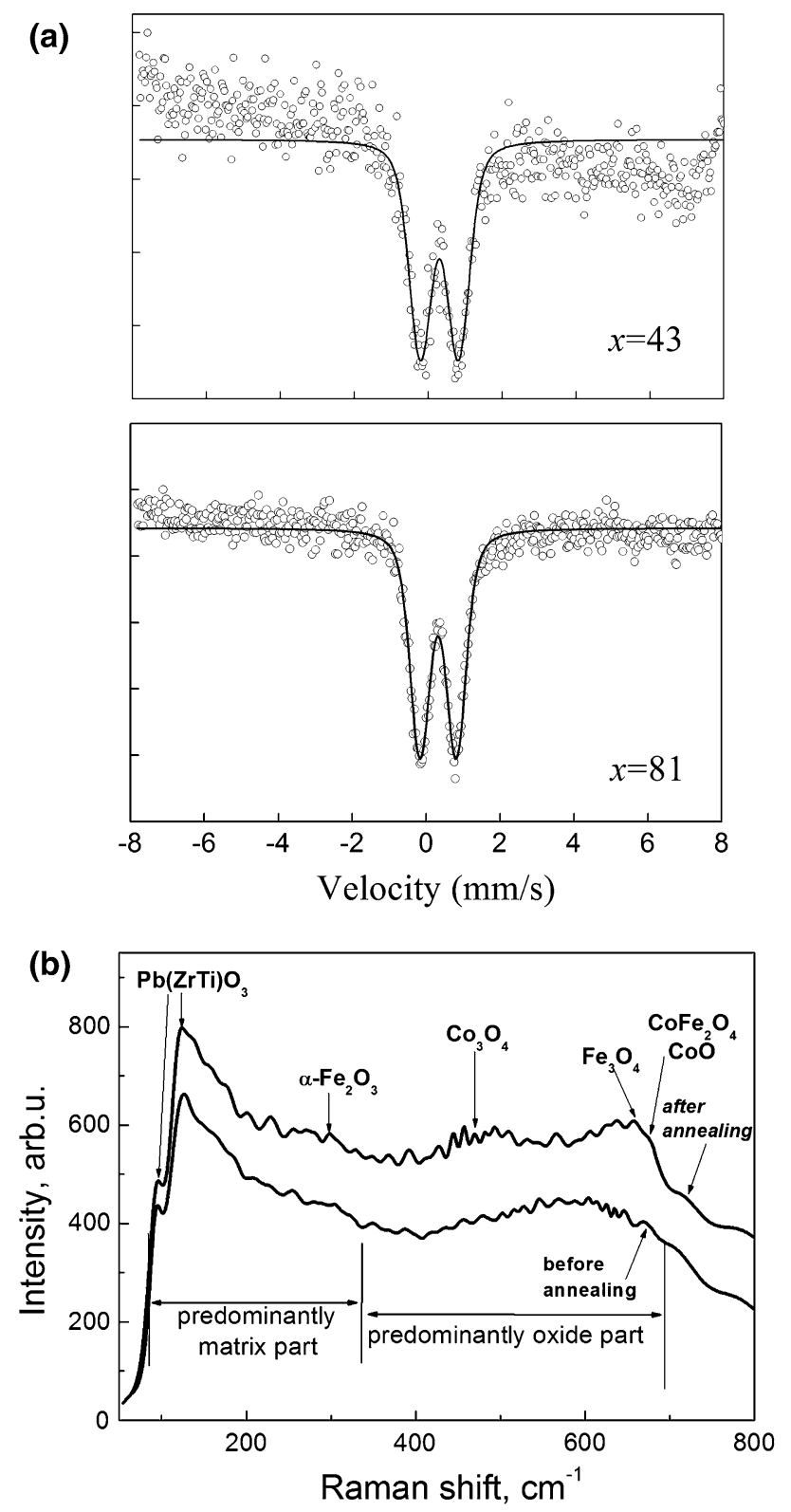

Fig. 2. Mössbauer spectra of $(\mathrm{FeCoZr})_{43}(\mathrm{PZT})_{57}$ and (Fe$\mathrm{CoZr}_{81}(\mathrm{PZT})_{19}$ films fabricated at $P_{\mathrm{O}}=3.7 \times 10^{-3} \mathrm{~Pa}(\mathrm{a})$ and $\mathrm{Ra}-$ man spectra of as-sintered and annealed $(\mathrm{FeCoZr})_{63}(\mathrm{PZT})_{37}$ fabricated at $P_{\mathrm{O}}=5.0 \times 10^{-3} \mathrm{~Pa}(\mathrm{~b})$.

of small wavenumbers $\left(90 \mathrm{~cm}^{-1}\right.$ to $\left.300 \mathrm{~cm}^{-1}\right)$ with Raman shifts very similar to those reported for $\mathrm{PbZrTiO}_{3}$ phase. ${ }^{26}$ In the region of large Raman shifts $\left(300 \mathrm{~cm}^{-1}\right.$ to $\left.700 \mathrm{~cm}^{-1}\right)$, the spectrum of the film annealed during $10 \mathrm{~min}$ at temperature of $600^{\circ} \mathrm{C}$ indicates also the presence of several peaks associated with various $\mathrm{Fe}$ and Co oxides in correlation with Mössbauer spectroscopy results. Shortterm annealing of film results in an increase of intensity and decrease in width of observed spectral lines, evidencing some crystallization of phases. ${ }^{26}$

$\mathrm{FeCoZr}-\mathrm{PbZrTiO}_{3}$ films synthesized at high oxygen partial pressures of $P_{\mathrm{O}} \geq 3.7 \mathrm{mPa}$ contained fully oxidized superparamagnetic nanoparticles of

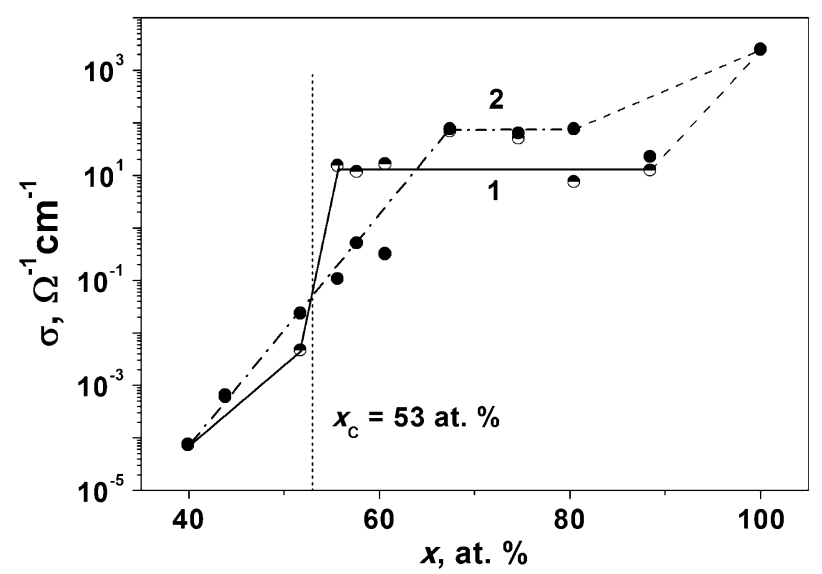

Fig. 3. Low-frequency conductivity, $\sigma_{\mathrm{L}}(f=100 \mathrm{~Hz})$ versus metallicphase content $(x)$ for the nanocomposite $\left(\mathrm{Fe}_{45} \mathrm{Co}_{45} \mathrm{Zr}_{10}\right)_{x}(\mathrm{PZT})_{(100-x)}$ films, as-deposited (1) and annealed at $T_{\mathrm{a}}=448 \mathrm{~K}$ (2).

either $\mathrm{Fe}(\mathrm{Co})_{3} \mathrm{O}_{4}$ or $\mathrm{Fe}(\mathrm{Co})_{2} \mathrm{O}_{3}$ oxides over the whole range of $x\left(x \leq 81\right.$ at.\%). ${ }^{22,26}$ This is confirmed by corresponding Mössbauer spectra shown in Fig. 2. An increase in the concentration of isolated oxide core/oxide shell nanoparticles is observed with $x$. In the absence of the $\left(\mathrm{Fe}_{x} \mathrm{Co}_{1-x}\right)_{1-\delta} \mathrm{O}$ phase, which was not detected in these strongly oxidized films, the superparamagnetic state of oxide nanoparticles is stabilized at $x>x_{\mathrm{c}}$, which may be caused by precipitation of the zirconium oxide formed at the nanoparticle/matrix interface. ${ }^{34}$ Thus, it is believed that $\mathrm{PbZrTiO}_{3}$ is a more friable matrix than alumina, as it does not assist in the conservation of the nonoxidized metallic cores in the nanoparticles during both the deposition and annealing procedures.

In the first step of electrical characterization of the composite samples, their percolation thresholds were determined. For this reason, preliminary measurements in the low-frequency $(100 \mathrm{~Hz})$ real part of the specific admittance $\left(\sigma_{\mathrm{L}}\right)$ versus metallicphase content $(x)$ at room temperature $\left(T_{\mathrm{p}}=303 \mathrm{~K}\right)$ were carried out. The preliminary measurements were carried out before (curve 1 in Fig. 3 ) and after (curve 2) the low-temperature annealing procedure (at $448 \mathrm{~K}$ ), when the oxidation of the nanoparticles was negligible. In accordance with the procedure developed in Ref. 35, $x_{\mathrm{c}}$ could be determined from the intersection of curves 1 and 2. This low-temperature heat treatment increased the electrical resistance of the as-deposited composite samples below $x_{\mathrm{c}}$, while they decreased above $x_{\mathrm{c}}$. The increase in the resistance for $x<x_{\mathrm{c}}$ was caused by structural relaxation of the dielectric matrix and the increasing distance between the nanoparticles (caused by partial agglomeration of some of them). The decrease in the electrical resistivity of the composites for $x>x_{\mathrm{c}}$ was associated with structural relaxation of the nanoparticles. For this reason, the point of intersection of the $\sigma_{\mathrm{L}}(x)$ curves for the asdeposited and annealed composites can be considered to be the percolation threshold. 
The behavior of the $\sigma_{\mathrm{L}}(x)$ dependence is shown in Fig. 3. For the as-deposited samples, three nearly linear regions in the $\sigma_{\mathrm{L}}(x)$ dependence with different slopes in curve 1 could be separated. The first region with $x$ between 39.9 at.\% and $\sim 52$ at.\% corresponds to $\sigma_{\mathrm{L}}$ increasing by approximately two orders of magnitude. In the second (very narrow) region with 52 at. $\%<x<55.5$ at. $\%$, where curves 1 and 2 intersect, a sharp increase in $\sigma_{\mathrm{L}}$ by almost four orders of magnitude was observed. At higher $x$ values, curve 1 in Fig. 3 was saturated, possessing a nearly constant $\sigma_{\mathrm{L}}$ value (shelf) with $x$ growth up to the highest concentration of metallic atoms. Based on this analysis, the metallic-phase concentration $x_{\mathrm{c}} \approx 53 \pm 2$ at. $\%$ can be considered as the percolation threshold at which the electrically contacting nanoparticles form the first percolating cluster. In this case, the concentration $x \approx 55.5$ at. $\%$ at the beginning of the shelf could be considered as the concentration corresponding to the onset of the whole net of high-conductive (percolating) clusters that formed in the as-deposited composites. The observed $x_{\mathrm{c}}$ is very close to the magnitudes of 55 at.\% to 56 at.\% detected for as-deposited $\left(\mathrm{Fe}_{45} \mathrm{Co}_{45} \mathrm{Zr}_{10}\right)_{x}\left(\mathrm{PbZrTiO}_{3}\right)_{(100-x)}$ films (see Fig. 3a in Ref. 19) and to $x_{\mathrm{c}} \approx 54$ at.\% observed for $\left(\mathrm{Fe}_{45} \mathrm{Co}_{45} \mathrm{Zr}_{10}\right)_{x}\left(\mathrm{Al}_{2} \mathrm{O}_{3}\right)_{(100-x)}$ nanocomposites produced with closed sputtering regimes (see Fig. $3 \mathrm{~b}$ in Ref. 19).

The complex behavior described for curve 1 in Fig. 3 (in particular, the sharp bend at $x \approx 52 \%$ ) strongly correlates with the similar behavior of $\sigma_{\mathrm{L}}(x)$ that was observed for different frequencies in the as-deposited samples, deposited with closed regimes. ${ }^{19,22}$ Based on the Mössbauer, Raman, and extended x-ray absorption fine structure spectroscopy measurements, the complex $\sigma_{\mathrm{L}}(x)$ behavior below the percolation threshold was attributed to the competition between the formation of an insulating $\left(\mathrm{Fe}_{x} \mathrm{Co}_{1-x}\right)_{1-\delta} \mathrm{O}$ core oxide and a semiconducting $\gamma-\mathrm{Fe}(\mathrm{Co})_{2} \mathrm{O}_{3}$ shell oxide with $x$ growth. ${ }^{19,22}$ The output of curve 1 on the shelf at $x>x_{\mathrm{c}}$ can be explained by the competition between two processes during deposition: ${ }^{26}$ the progressive oxidation of the metallic nanoparticles with increasing $x$ [resulting in $\sigma_{\mathrm{L}}(x)$ decreasing] at $x<x_{\mathrm{c}}$, and the tendency to form a less resistive (percolating) net from the oxidized nanoparticles [resulting in $\sigma_{\mathrm{L}}(x)$ increasing because of the significant decrease in the dielectric matrix fraction in the films] at $x>x_{\mathrm{c}}$.

Curve 2 in Fig. 3 shows that, after the samples were annealed at $T_{\mathrm{a}}=448 \mathrm{~K}$, the $\sigma_{\mathrm{L}}(x)$ dependence changed radically and became linear in the region of 39.9 at. $\%<x<67$ at. $\%$. In the concentration range of 52 at.\% to 60 at.\%, the $\sigma_{\mathrm{L}}$ values were reduced by almost two orders of magnitude compared with that in the as-deposited sample. When approaching the shelf with an almost constant $\sigma_{\mathrm{L}}(x)$, it was assumed that the concentration was $x \approx 67$ at. $\%$, which is associated with the onset of the formation of a percolation net in the annealed nanocomposites. The shelf began to shift to a metallic phase with a higher concentration after annealing, confirming the additional oxidation of the CoFeZr nanogranules. There was a small excess in $\sigma_{\mathrm{L}}$ at $x>67$ at.\% after annealing, compared with the $\sigma_{\mathrm{L}}$ values in the asdeposited state, in the region where the shelf was caused by an increase in the volume fraction of the semiconducting $\gamma-\mathrm{Fe}(\mathrm{Co})_{2} \mathrm{O}_{3}$ oxide during the annealing procedure. As seen in Fig. 3, the value of $\sigma_{\mathrm{L}}$ for a fully metallic $\left(\mathrm{Fe}_{45} \mathrm{Co}_{45} \mathrm{Zr}_{10}\right)$ film with $x=100$ at. $\%$ was 100 times higher than that obtained for a composite film with the maximum concentration of metallic atoms at $x=88.4$ at.\%. This also confirms the strong influence of the oxidation on the admittance of the composites.

The next step was to verify the adequacy of the developed AC hopping conductance model to explain the hopping nature of the NC effect in the annealed nanocomposites. To do this, the samples were annealed at higher temperatures to intensify the oxidation of the FeCoZr-based nanoparticles inside the $\mathrm{PbZrTiO}_{3}$ matrix. In accordance with the developed model and our previous experiments, the $\mathrm{NC}$ effect is usually exhibited in the form of two peculiarities: a positive phase shift $(\theta)$ between the applied voltage and current, and also sigmoid-like dependences of the real part of $\sigma(f)$.

To demonstrate the adequacy of the developed model, Fig. 4 shows typical $\sigma(f)$ dependences obtained at different temperatures $\left(T_{\mathrm{p}}\right)$ for a sample with $x=51.7$ at. $\%$ annealed at $T_{\mathrm{a}}=573 \mathrm{~K}$, when the amount of oxidation was significant. After annealing, this sample displayed a sigmoid-like $\sigma(f)$ dependence [and positive $\theta(f)$ values, as shown in the inset in Fig. 4] over the whole $f$ range and for all of the temperatures studied.

Moreover, in the low-frequency region $\left[\sigma_{\mathrm{L}}\left(f_{\mathrm{L}}\right) \approx\right.$ const.], the value of $\sigma_{\mathrm{L}}$ at $f<f_{\mathrm{L}}$ was strongly dependent on temperature (Fig. 4). In particular, the $\sigma_{\mathrm{L}}$ values in this frequency region

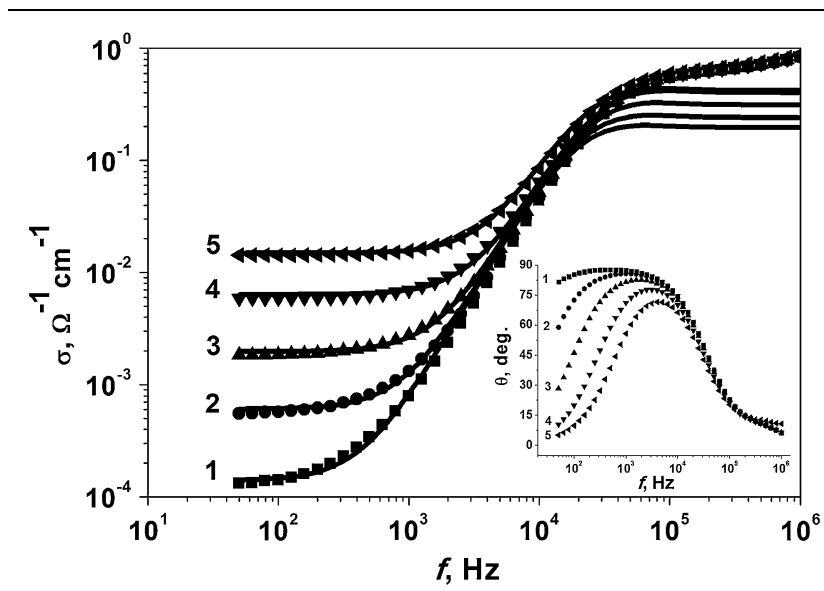

Fig. 4. Real part of the admittance versus frequency $\sigma(f)$ for $\left(\mathrm{Fe}_{45}\right.$ $\left.\mathrm{Co}_{45} \mathrm{Zr}_{10}\right)_{51.7}(\mathrm{PZT})_{48.3}$ nanocomposite films (dots) and the simulated curves (solid lines): 1-168 K, 2-198 K, 3-228 K, 4-258 K, $5-288 \mathrm{~K}$. Inset experimental $\theta(f)$ dependences. 


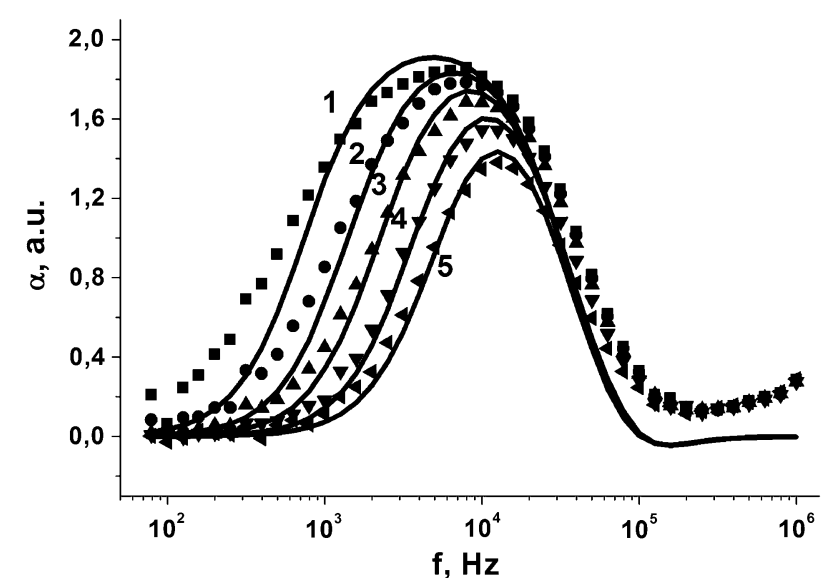

Fig. 5. Factor $(\alpha)$ versus frequency $(f)$ for an annealed $\left(\mathrm{Fe}_{45}\right.$ $\left.\mathrm{Co}_{45} \mathrm{Zr}_{10}\right)_{51.7}(\mathrm{PZT})_{48.3}$ nanocomposite sample extracted from the experimental (dots) and simulation (solid lines) estimations: 1-168 K, 2-198 K, 3-228 K, 4-258 K, 5-288 K.

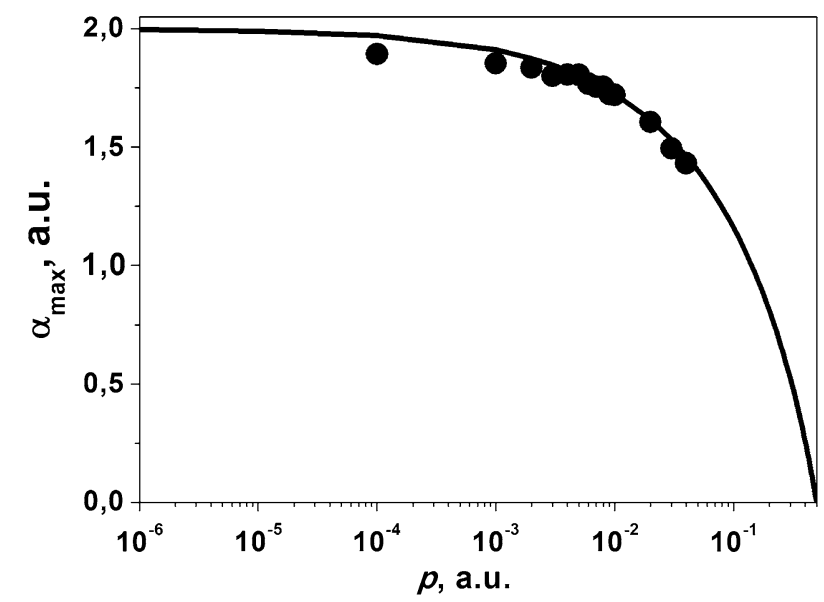

Fig. 6. Maximum values of the frequency factor $\left(\alpha_{\max }\right)$ versus electron jump probability $(p)$ for an $\left(\mathrm{Fe}_{45} \mathrm{Co}_{45} \mathrm{Zr}_{10}\right)_{51.7}(\mathrm{PZT})_{48.3}$ nanocomposite sample: experimental data (dots) and simulation results (solid line).

increased with temperature, confirming the activational characteristics of the AC conductance in the studied temperature range. Moreover, the width of the $f_{\mathrm{L}}$ range with $\sigma_{\mathrm{L}} \approx$ const. increased from $100 \mathrm{~Hz}$ to $1000 \mathrm{~Hz}$ with increasing temperature. In the high-frequency region, the situation was very similar: while the $\sigma_{\mathrm{H}}\left(f_{\mathrm{H}}\right)$ curves did not saturate, they converged to one line with very small growth of $\sigma_{\mathrm{H}}\left(f_{\mathrm{H}}\right)$ with increasing $f$ at $f>f_{\mathrm{H}} \approx 50 \mathrm{kHz}$ to $60 \mathrm{kHz}$.

In the intermediate frequency range of $(100 \mathrm{~Hz}$ to $1000 \mathrm{~Hz})<f_{\mathrm{M}}<f_{\mathrm{H}}$, very strong $\sigma_{\mathrm{M}}\left(f_{\mathrm{M}}\right)$ dependences were observed, which can be described by Eq. 2. Then, as follows from the model, ${ }^{15,19}$ to check the validity of the developed model for the annealed samples, the probability $(p)$ of the next electron jump after the first one needed to be calculated under the application of an AC bias voltage. It was shown in the "Introduction" that, for the simplest

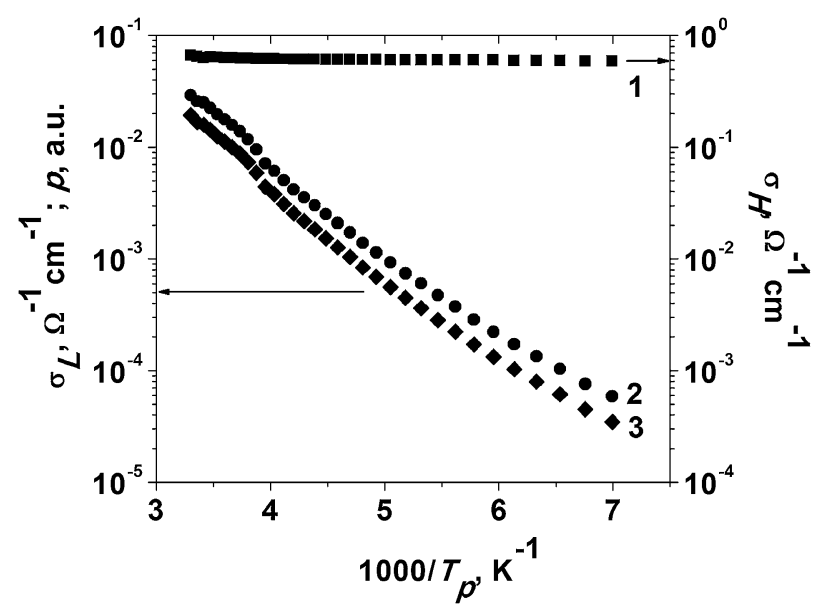

Fig. 7. Temperature dependences of the low-frequency $\sigma_{\mathrm{L}}$ for $f=100 \mathrm{~Hz}(1)$, the high-frequency $\sigma_{\mathrm{H}}$ for $f=300 \mathrm{kHz}$ (2), and the electron jump probability $(p)(3)$ on Arrhenius scales for an annealed nanocomposite $\left(\mathrm{Fe}_{45} \mathrm{Co}_{45} \mathrm{Zr}_{10}\right)_{51.7}(\mathrm{PZT})_{48.3}$ sample.

case, when the $\sigma(f)$ dependences display sigmoidlike behavior in the studied frequency range, the probability can be extracted with the simple equation

$$
p=\frac{\sigma_{\mathrm{L}}}{2 \sigma_{\mathrm{H}}} .
$$

All of the mathematical relationships that describe the AC hopping model as well as the simulation software for AC conductance, used to estimate the $\sigma(f, p)$ and $\alpha(f, p)$ dependences, are presented in Ref. 15. The model was improved in Ref. 36 to take the unequal distances between the nanoparticles and their size distribution into account, such that the lifetime $\left(\tau_{\mathrm{m}}\right)$ of an electron in a nanoparticle in Eq. 1 is not constant, having some distribution.

In Fig. 4, the solid lines represent the $\sigma(f)$ dependences, calculated using the discussed model. The values obtained experimentally for the $\left(\mathrm{Fe}_{45}\right.$ $\left.\mathrm{Co}_{45} \mathrm{Zr}_{10}\right)_{51.7}\left(\mathrm{PbZrTiO}_{3}\right)_{48.3}$ sample were in accordance with the simulations.

Figure 5 shows very good agreement between the frequency dependences of the $\alpha$ factor in the Mott Eq. 2, which were extracted from both the experimental data and the corresponding simulations.

Figure 5 shows that the $\alpha(f)$ dependences exhibit a distinct maximum, in correlation with the model. $\alpha_{\max }$ is shown in Fig. 6 as a function of $p$. The solid line in Fig. 6 represents the dependence of $\alpha_{\max }(p)$, obtained from simulations at different temperatures. The experimental data points (dots) in Fig. 6, calculated from $\sigma(f)$ for various $T_{\mathrm{p}}$ values in Fig. 4 using formula (3), also show very good agreement between the experimental and simulation results.

To estimate the activation energy of dipole formation (hopping conductance), Fig. 7 presents the temperature dependences of the low-frequency $\sigma_{\mathrm{L}}$ 
$(f=100 \mathrm{~Hz})$, high-frequency $\sigma_{\mathrm{H}}(f=300 \mathrm{kHz})$, and electron hopping probability $(p)$, which are Arrhenius plots. The linearization of these curves with an Arrhenius scale allowed for the activation energies to be estimated for AC hopping conductance as follows: $\Delta E\left(\sigma_{\mathrm{L}}\right)=0.153 \mathrm{eV}, \Delta E(p)=0.151 \mathrm{eV}$, and $\Delta E\left(\sigma_{\mathrm{H}}\right)=0.0013 \mathrm{eV}$.

A comparison between the straight lines of the slopes in Fig. 7 indicates that $\Delta E\left(\sigma_{\mathrm{L}}\right) \gg \Delta E\left(\sigma_{\mathrm{H}}\right)$. This is in accordance with the developed model. ${ }^{15,19}$ The higher $\Delta E\left(\sigma_{\mathrm{L}}\right)$ value can be explained as follows: When an electron jumps from the second nanoparticle (charged after the first jump) to the third one in the direction opposite to the applied AC electric field, it must overcome a potential barrier that appears from the formation of dipoles because the electron occupies the second nanoparticle. Alternatively, if the electron returns to the first nanoparticle (which is occupied by a hole), it will be attracted by its positive charge. This will lower the value of the activation energy $\left[\Delta E\left(\sigma_{\mathrm{H}}\right)\right]$ to nearly zero. Considering the almost zero slope of the $\sigma_{\mathrm{H}}$ versus $\left(1000 / T_{\mathrm{p}}\right)$ dependence in Fig. 7 , it can be concluded that the variations in $p$ versus $\left(1000 / T_{\mathrm{p}}\right)$ were caused by the great extent of the $\sigma_{\mathrm{L}}$ versus $\left(1000 / T_{\mathrm{p}}\right)$ dependence (see Eq. 3). For this reason, $\Delta E(p) \approx \Delta E\left(\sigma_{\mathrm{L}}\right)$.

From the presented dependences of the real part of the admittance $\sigma(f, T)$ for $\left(\mathrm{Fe}_{45} \mathrm{Co}_{45} \mathrm{Zr}_{10}\right)_{x}$ $(\mathrm{PZT})_{(100-x)}$ nanocomposite films, it can be concluded that, after annealing, they (a) displayed an NC effect over the whole temperature ( $100 \mathrm{~K}$ to $300 \mathrm{~K})$ and frequency $(100 \mathrm{~Hz}$ to $1 \mathrm{MHz})$ ranges, and (b) could be well described by the developed AC hopping conductance model. $9,15,19,22$

\section{CONCLUSIONS}

It was established that the real part of $\sigma(f)$ for annealed $\left(\mathrm{Fe}_{45} \mathrm{Co}_{45} \mathrm{Zr}_{10}\right)_{x}\left(\mathrm{PbZrTiO}_{3}\right)_{(100-x)}$ films displayed sigmoid-like behavior, accompanied with positive phase shifts between the current and voltage applied over the whole frequency and temperature ranges studied. This behavior confirms that the $\sigma(f, T)$ dependences followed the known Mott relationship $\sigma(f) \sim f^{\alpha}$. However, in accordance with the developed AC hopping model, the exponent $0<\alpha<2$ is the so-called frequency factor, which determines the probability of electron jumping. It is therefore dependent on the frequency (compared with the known Mott model with $\alpha \approx 0.8$ ). The experimental data and simulation results based on the hopping conductivity model showed very good agreement and allowed a hopping conductance activation energy of $\sim 0.15 \mathrm{eV}$ to be estimated.

\section{ACKNOWLEDGEMENTS}

This study was carried out in the framework of the Research Project No. IP 2012026572 within the Iuventus Plus program of the Polish Ministry of
Science and Higher Education in the years 20132015.

\section{CONFLICT OF INTEREST}

The authors declare that they have no conflict of interest.

\section{OPEN ACCESS}

This article is distributed under the terms of the Creative Commons Attribution License which permits any use, distribution, and reproduction in any medium, provided the original author(s) and the source are credited.

\section{REFERENCES}

1. A.D. Pogrebnjak, A.P. Shpak, G.V. Kirik, N.K. Erdybaeva, M.V. Il'yashenko, A.A. Dem'yanenko, Y.A. Kunitskii, A.S. Kaverina, V.S. Baidak, N.A. Makhmudov, P.V. Zukowski, F.F. Komarov, V.M. Beresnev, S.M. Ruzimov, and A.P. Shypylenko, Acta Phys. Pol. A 120, 94 (2011).

2. A.D. Pogrebnjak, M.M. Danilionok, V.V. Uglov, N.K. Erdybaeva, G.V. Kirik, S.N. Dub, V.S. Rusakov, A.P. Shypylenko, P. Zukovski, and Y.Z. Tuleushev, Vacuum 83, S235 (2009).

3. J. Kúdelčík, Eur. Phys. J. Appl. Phys. 50, 11002 (2010).

4. J. Kúdelčík, P. Bury, J. Drga, P. Kopčanský, V. Závišová, and M. Timko, J. Magn. Magn. Mater. 326, 75 (2013).

5. R.S. Iskhakov, S.V. Komogortsev, E.A. Denisova, Yu.E. Kalinin, and A.V. Sitnikov, JETP Lett. 86, 465 (2007).

6. R.S. Iskhakova, E.A. Denisova, S.V. Komogortsev, L.A. Chekanova, Y.E. Kalinin, and A.V. Sitnikov, Phys. Solid State 52, 2263 (2010).

7. P. Zhukowski, J. Sidorenko, T.N. Kołtunowicz, J.A. Fedotova, and A.V. Larkin, Prz. Elektrotechn. 86, 296 (2010).

8. P. Zhukowski, T.N. Kołtunowicz, J.A. Fedotova, and A.V. Larkin, Prz. Elektrotechn. 86, 157 (2010).

9. T.N. Koltunowicz, P. Zukowski, M. Milosavljević, A.M. Saad, J.V. Kasiuk, J.A. Fedotova, YuE Kalinin, A.V. Sitnikov, and A.K. Fedotov, J. Alloys Compd. 586, S353 (2014).

10. R. Skomski, J. Phys. 15, R841 (2003).

11. Y. Imry, Introduction to Mesoscopic Physics, 2nd ed. (Oxford: Oxford University Press, 2002), p. 236.

12. D. Stauffer and A. Aharony, Introduction to Percolation Theory (London: Taylor \& Francis, 2003), p. 192.

13. A.M. Saad, A.V. Mazanik, Y.E. Kalinin, J.A. Fedotova, A.K. Fedotov, S. Wrotek, A.V. Sitnikiov, and I.A. Svito, Rev. Adv. Mater. Sci. 8, 152 (2004).

14. A. Saad, A.K. Fedotov, I.A. Svito, J.A. Fedotova, B.V. Andrievsky, Y.E. Kalinin, V. Malyutina-Bronskaya, A.A. Patryn, A.V. Mazanik, and A. Sitnikiov, J. Alloys Compd. 423, 176 (2006).

15. T.N. Kołtunowicz, P. Zhukowski, V.V. Fedotova, A.M. Saad, A.V. Larkin, and A.K. Fedotov, Acta Phys. Pol. A 120, 35 (2011).

16. P. Zhukowski, T.N. Koltunowicz, J. Partyka, Y.A. Fedotova, and A.V. Larkon, Vacuum 83, S275 (2009).

17. A.V. Larkin, A.K. Fedotov, J.A. Fedotova, T.N. Koltunowicz, and P. Zhukowski, Mater. Sci. 30, 75 (2012).

18. L. Bakueva, G. Konstantatos, S. Musikhin, H.E. Ruda, and A. Shika, Appl. Phys. Lett. 85, 3567 (2004).

19. T.N. Kołtunowicz, J.A. Fedotova, P. Zhukowski, A. Saad, A. Fedotov, J.V. Kasiuk, and A.V. Larkin, J. Phys. D 46, 125304 (2013).

20. T.N. Kołtunowicz, P. Zhukowski, A.K. Fedotov, A.V. Larkin, A. Patryn, B. Andriyevskyy, A. Saad, J.A. Fedotova, and V.V. Fedotova, Elektron. Elektrotechn. 19, 37 (2013).

21. T.N. Kołtunowicz, P. Zhukowski, V. Bondariev, J.A. Fedotova, and A.K. Fedotov, Acta Phys. Pol. A 123, 932 (2013).

22. J. Fedotova, T.N. Koltunowicz, and P. Zhukowski, Transport of charges and structural properties of selected metal- 
dielectric nanocomposites (Lublin: Politechnika Lubelska, 2012) (In Polish).

23. N.F. Mott and E.A. Davis, Electron Processes in Non-crystalline Materials (Oxford: Clarendon, 1979).

24. I. Svito, A.K. Fedotov, T.N. Koltunowicz, P. Zhukowski, Y. Kalinin, A. Sitnikov, K. Czarnacka, and A. Saad, J. Alloys Compd. 615, S371 (2014).

25. T.N. Koltunowicz, Acta Phys. Pol. A 125, 1412 (2014).

26. YuV Kasyuk, J.A. Fedotova, M. Marszalek, A. Karczmarska, M. Mitura-Nowak, YuE Kalinin, and A.V. Sitnikov, Solid State Phys. 54, 178 (2012).

27. YuE Kalinin, A.T. Ponomarenko, A.V. Sitnikov, and O.V. Stogney, Phys. Chem. Mater. Treat. 5, 14 (2001).

28. I.V. Zolotukhin, YuE Kalinin, A.T. Ponomarenko, V.G. Shevchenko, A.V. Sitnikov, O.V. Stognei, and O. Figovsky, J. Nanostruct. Polym. Nanocompos. 2, 23 (2006).

29. J. Fedotova, Yu. Kasiuk, A. Larkin, J. Przewoznik, C. Kapusta, and Yu. Kalinin, Proceedings of the 54th Internationales Wissenschaftliches Kolloquium - Information technology and electrical engineering-devices and systems, materials and technology for the future (54-IWK), ed. By F. Berger, (Ilmenau University of Technology, Ilmenau, 2009).

30. J. Przewoznik, C. Kapusta, M. Milosavljevic, YuV Kasiuk, J. Zukrowski, M. Sikora, A.A. Maximenko, D. Szepietowska, and K.P. Homewood, J. Phys. D 44, 495001-1 (2011).

31. T.N. Kołtunowicz, Pomiary Automatyka Kontrola (Measurement Automation and Monitoring) 57, 694 (2011).

32. T. Kołtunowicz, Elektronika-konstrukcje, technologie, zastosowania 48, 37 (2007).

33. J.A. Fedotova, Acta Phys. Pol. A 125, 1418 (2014).

34. J.V. Kasiuk, J.A. Fedotova, J. Przewoznik, J. Zukrowski, M. Sikora, C.Z. Kapusta, A. Grce, and M. Milosavljević, J. Appl. Phys. 116, 044301-1 (2014).

35. L.V. Lutsev, YuE Kalinin, A.V. Sitnikov, and O.V. Stogney, Phys. Solid State 44, 1889 (2002).

36. P.V. Zukowski, J. Partyka, P. Wagierek, Yu Shostak, Yu Sidorenko, and A. Rodzik, Semiconductors 34, 1124 (2000). 